\title{
Science Studies
}

an Interdisciplinary Journal for Science and Technology Studies

\section{Volume 14, Number 1, 2001}

\section{Articles}

Janet Atkinson-Grosjean, Dawn House and Donald Fisher:

Canadian Science Policy and Public Research Organisations in the 20th Century

Karoliina Snell:

The Weakening Connection Between Education and Research:

A Study of Three University Departments

\section{Discussion}

Sandra Harding:

Multiculturalism and Postcolonialism: What Difference

Do They Make to Western Scientific Epistemology?

Janice Newson and Claire Polster:

Reclaiming Our Centre:

Towards a Robust Defence of Academic Autonomy

Visit our web-site at

\section{http://www.valt.helsinki.fi/kfil/tt/}

The site includes an index of all the Science Studies volumes since 1988. 
」I 


\title{
Canadian Science Policy and Public Research Organisations in the $20^{\text {th }}$ Century
}

\author{
Janet Atkinson-Grosjean, Dawn House and Donald Fisher
}

\begin{abstract}
Across OECD nations, public/private partnerships have recently become popular mechanisms in advancing science and technology policies. But Canada has a long tradition of such partnerships. The federal government was involved in the promotion of relations between public research organisations (PROs) and the private sector as early as the start of the twentieth century. In this paper, we trace the evolution of policies promoting the economic utility of public science in Canada. We then present the National Research Council's Industrial Research Assistance Program (NRCIRAP) and Industry Canada's Networks of Centres of Excellence (NCE) program as contrasting cases of federal steering. By developing an understanding of these flagship instruments, we seek insight into the wider implications of state intervention in relations between PROs and Canadian industry.
\end{abstract}

In Canada, as in other OECD countries, national policies promote closer ties between public research organisations $(\mathrm{PROs})^{1}$ and the economic mainstream: public science is moving out of academic and government labs and into the marketplace. Policy goals include the commercialisation of research results as proprietary products and the adoption of new market-friendly institutional arrangements for the conduct of research. Policy tools like intellectual property rights and public/private research networks promote the development of closer academy-industry relations and facilitate what can loosely be called the privatisation of the public knowledge base.

While this constellation of factors may seem novel, Canada has a long tradition of state involvement in the promotion of public-private collaborations. The economic utility of scientific research was recognised as early as the start of the twentieth century, when public science was first harnessed to the needs of private industry. In this paper, we trace the evolution of these policies in Canada during the $20^{\text {th }}$ century and present the National Research Council's Industrial 
Research Assistance Program (NRCIRAP) and Industry Canada's Networks of Centres of Excellence (NCE) program as contrasting cases of federal steering. By developing an understanding of these flagship instruments, we seek insight into the wider implications of state intervention to foster closer relations between PROs and Canadian industry.

\section{Overview}

As historian Donald Phillipson has commented, while interactions between Canadian PROs and industries are not thoroughly documented, they offer a fruitful and interesting field of study. ${ }^{2}$ There are three principal reasons why this is the case. First, until recently, because of the country's small population and relative youth, "everybody knew everyone else" at the senior levels of industrial, academic and government science. As John Porter (1965: 507-511) found, there was a tendency for top-tier Canadian scientists to hold interlocking positions of power in government and university sectors-C.W. Mills (1956) famously referred to a parallel phenomenon in the USA as "The Power Elite". For a century up to the 1960s, government science in Canada was very much the enterprise of a small elite group of scientists, e.g. J.W. Dawson, J.H. Grisdale, Charles Camsell, C.J. Mackenzie and E.W.R. Steacie. ${ }^{3}$ These men, and others like them in academy and industry, shared similar socio-economic backgrounds - most were Canadian-born of British extraction, middleclass in origin and Protestant (Porter, 1965: 509). They personally knew "everyone that mattered". The "scientific research field" (Bourdieu 1969: 1988) was inclusive and relatively small. This net- work depended as much on shared social capital as it did on academic or scientific capital. This is illustrated in C.J. Mackenzie's response to a journalist on whether it was difficult to get government approval when the NRC established a nuclear research unit during the Second World War. Mackenzie replied,

\begin{abstract}
It was surprisingly easy. In those days the NRC reported to C.D. Howe [then Minister of Department of Trade and Commerce].... C.D. was a particular friend of mine.... We all went to C.D.'s office and discussed the idea with him. I remember he sat there and listened to the whole thing, then he turned to me and said: 'What do you think?' I told him I thought it was a sound idea, then he nodded a couple of times and said: 'Okay, let's go.' (B. Lee, 'The Atom Secrets,' Globe Magazine, October 28, 1961; cited in Porter, 1965: 432)
\end{abstract}

Although Mackenzie's story may be an exaggeration, for most of the country's history, policy making was personal; it operated on a "social capital" system. Decisions were made on the basis of whom one knew.

That situation began to be questioned in the 1960s. On one hand, the Canadian science community was part of the expansion of the whole university system. On the other, the personalist system began to be perceived as both corrupt and inefficient (Glassco, 1962). In the face of demands that decisions follow "scientific" methods complete with rational justifications, the personalist system went underground. So the story of Canadian science policy is in large part the story of the people who made it. The evolution of policy attitudes towards consorting with industry reflects the evolution in elite ways of thinking on the topic.

A second aspect of interest is that 
awareness of other national models -predominantly American and British- has shaped Canadian policy throughout the century. In comparison to other advanced nations, we tend to feel we lag scientifically and this has always influenced the projects undertaken. So international trends in policy promote the adoption of particular models, or "isomorphic convergence" (Powell \& DiMaggio, 1983; see also Garrett \& Lange, 1996; Unger \& van Waarden, 1995). Canada's National Research Council, for example, was an example of isomorphic convergence with similar bodies in Britain and the USA, when it was founded in 1916.

At the same time, we adapt these models to the Canadian context. Institutional path-dependence and our particular cultural legacies promote a countervailing trend for divergence (Banting, Hoberg \& Simeon, 1997). Canada's Networks of Centres of Excellence program, founded in the late 1980 s, is an example. While the phrase "centres of excellence" was appearing with increasing regularity in the international policy discourse at the time, the Canadian innovation was to network these centres together. It created a national research capacity while side-stepping potential problems of Canadian federalism and geography; such as provincial jurisdiction over education, university autonomy, the federal requirement to serve all regions equally and the sheer size of the country. The IRAP program, established 1962, is also a peculiarly Canadian solution to geographic problems. Rather than hire technically trained civil servants to give hands-on advice to all sorts of different industries, in every region of the country, IRAP created a mechanism for borrowing them.
Approximately two-thirds of IRAP's field agents are locals, co-opted from industries and universities. They are a "field army" (NRC-IRAP interviews, January 2001) who know their regions, closely identify with their industrial clients and enjoy an enormous amount of autonomy from the Ottawa bureaucracy.

A third element of interest is that the boundaries between public and private in Canadian scientific institutions are quite unstable and tend to evolve quickly. Phillipson (2000) provides the example of the Ontario Research Foundation (ORF). Founded by the province in the Depression era as a rival to the federal National Research Council, ORF was transformed into a successful autonomous public industrial laboratory, a Crown agency, in the 1950s. Later, it was "privatised" into a state-owned corporation. Subsequently, the shares were bought by a commercial company. Another example is the Canadian Standards Association (CSA). Founded in the early 1920 s as a government-funded advisory committee of researchers and industrialists, it was incorporated as a company in 1940, with the approval of a government preoccupied with war research. CSA then moved its laboratories from Ottawa, the federal capital, to Toronto, the leading industrial city. Here, it became a self-financing independent institution, and is still authorised to promulgate and enforce standards.

Keeping these three facets of interest in mind, we next present a conceptual frame that attempts to capture the significance of the slippage between public and private science and technology. We then move to a historical review. Starting with the founding of the National Research Council in 1916, and fol- 
lowing the evolution of that body, our review is structured around two key moments in Canadian science policy history: the Glassco Commission (196062) and the Lamontagne Committee (1968-77). Through the reports of these bodies, we seek to map shifting understandings of the proper domains of PROs and industry, and public and private knowledge, over the years. In the final section, we present the NRC-IRAP and NCE programs as contrast cases of hybrid organisational forms that attempt, with some success, to occupy a shifting third space between public and private science, and between academic and industrial values.

\section{The Public/Private Divide}

The public/private demarcation is one of the core sociological distinctions. Norberto Bobbio calls it one of the "grand dichotomies" of western thought (Bobbio, 1989; cited in Weintraub, 1997: 1). For much of the second half of the $20^{\text {th }}$ century, the distinction provided a useful shorthand for thinking about the organisation of science. The public/private axis mapped neatly onto the classic linear model of the research process: public science undertook the basic research that private science then developed and commercialised. Public science happened in government and university labs and was freely disseminated in the form of journal publications. Private science happened in industrial labs; its commercial techniques were secret and "protected" as intellectual property. Further, public science stepped forward where private science stepped aside - in "public good" situations of market failure where there was insufficient incen- tive for private-sector investment. (But note the argument of Callon [1994], that basic science is a public good not 'by nature' but by design. According to Callon, it takes a great deal of effort and investment to maintain science in the public domain; economic definitions of public and private are misguided, and need to be replaced by broader understandings of local and extended networks of heterogeneous elements.)

The elegance of this model had little to do with the messy reality of the way science was really done. Invoking a clean separation between public and private, basic and applied, open and secret, was a politically expedient move geared to maintain wartime levels of government funding for research. Despite its artificiality, however, the linear model dominated science policy for the next three decades. The funding of basic (public) research was justified in terms of its eventual but distant (private) payoff which would, in turn, generate future (public) returns in the form of tax revenues, employment and technological innovations. Because of the power of resource allocations from the state, the linear model became, in effect, a self-fulfilling prophecy, constructing real divisions from imagined boundaries.

But those stable demarcations began to lose their shape in the 1970s. The decade began with recession, oil shocks and great economic instability in traditional industries; these crises called into question many of the post-war welfarestate settlements. The mid-1970s saw the patenting of the first products of the revolution in molecular biology. As publicly funded discoveries were privatised in the form of biotechnology patents, the former distance between public and pri- 
vate science began to close. At the same time, the tension between (public) openness and (private) secrecy came to the fore as life scientists began to engage in commercialisation. As the 1970s ended, "new right" governments worldwide began to reform their public sector institutions, including universities and research funding agencies. Market criteria and corporate structures were imported from the private sector and applied to public agencies, enterprises and government departments.

From the early 1980s on, federal science and technology policy has been housed in fundamental shifts in the relation between academic research and the economy and between the public and private spheres. Economic rationalism and the dominance of neo-liberal market ideology guide government policy and have become the catalysts for change. Accountability and relevance are translated into closer links between public research and the market. Technology transfer and the commodification of knowledge are defined as the essential foundations for economic restructuring and greater international competitiveness.

The clear intention is to press market relations, and therefore the power of capital, into public research organisations where previously non-market or quasi-market models were in operation. All institutions are pushed toward what Burchell (1996) calls "enterprise culture". The enhancements offered by successive federal governments to narrow the gap between public science and industry are part of the inescapable tension between the welfare state and market principles. Under welfare state capitalism, the state simultaneously supports commodity production and market exchange and redistributes resources to those systematically disadvantaged by these activities. But the State's ability to act is severely limited by the internal contradictions in capital (Offe, 1984; 1996.)

The changes in federal science and technology policy over the last century can best be understood and explained with reference to these internal contradictions. The hegemony of the market over the last two decades has allowed governments to intervene more forcibly than in earlier decades to lessen the gap between "R" and " $D$ "; that is, between Research (public; academic) and Development (private; industrial). Following Offe, the IRAP and NCE programs can be seen as successive attempts by the state to intervene in the exchange process and encourage the commodity form of production. For Bourdieu $(1969 ; 1988)$ these same policies represent an increasing effort to redraw the contours of the academic "field" of scientific research by tipping the balance between economic capital and scientific capital in public research organisations (see also Ringer, 1992).

When public science, private industry and the state become partners in the privatisation of research, does it make sense, any more, to maintain an analytical distinction between public and private enterprise? Is it a difference that makes no difference? If the distinction collapses or is abandoned, what is lost? What do "public" and "private" mean today in terms of science policy and scientific practice? In this paper, we address these questions through our research into public research organisations and Canadian science policy. ${ }^{4}$ 


\section{Evolution of Science Policies in Canada}

Canada's size, its low population density and small proportion of secondary industry encouraged government to take an early lead in scientific development. Federal scientific activities concentrated on practical applications and the exploitation of the country's natural resources. The first federally supported science initiative was the Geological Survey of Canada, founded in 1841, which laid the basis for the mining industry. In the 1880 s federal support of astronomy produced longitudinal maps used in building the railways. The creation of experimental farms patterned after the USA's land grant movement produced innovations suited to a cold climate and large gains in agricultural productivity. Marine research stations for the fishing industry developed in the 1890s, followed by forestry experimental stations. Before the end of the 19th century, several federal government departments had established national laboratories for the exploitation of natural resources.

Events engendered by the First World War pressured the government to take action in developing science and technology for the needs of an emergent secondary industry. The earliest stimulus came in 1915 from the business sector. Hampered by war-time cuts in processed materials and manufactured goods, several Canadian industrialists, with the endorsement of university officials, urged the government to provide universities with financial support to conduct industrial research (Thistle, 1966: 4-5). While no concrete action resulted from these particular proposals, external forces set the stage for govern- ment action in the following year.

\section{The National Research Council}

In 1916, Britain created a Department of Scientific and Industrial Research (DSIR), to help offset German dominance in science and technology. Dominions of the Empire, such as Canada and Australia, were urged to do the same (Dufour \& de la Mothe, 1993: 8; Finnemore, 1993). The Canadian government appeared uninterested at first, but its hand was forced by the principal of McGill University, William Peterson, who had been invited to form a research alliance with the DSIR. If the Canadian government would not create a similar body to support university research, Peterson proposed to persuade his fellow university presidents to join forces with DSIR (Thistle, 1966: 6). On June 6, 1916, an Order-in-Council was passed to create the National Research Council (initially called the Honorary Advisory Council). In broad terms, its responsibilities were to plan, co-ordinate and direct research toward "the most practical and pressing problems indicated by industrial necessities" (cited in Lamontagne report, 1968-77, vol. 1: 27). As one of its first tasks, the NRC set out to gauge the state of industrial research in Canada. Survey results showed that only 37 of the 2,800 firms responding performed research on an ongoing basis and most of these employed only one researcher (Thistle, 1966: 29). These findings convinced the NRC that it had little to plan, co-ordinate or direct, and that Canadian industries were too primitive to conduct research of sufficient quality to contribute to their long-term development.

This conclusion motivated the NRC to 
form an alliance with the universities. In 1917 the NRC introduced post-graduate scholarships in the sciences in order to build a critical mass of researchers (Thistle, 1966: 26, 127). The idea of constructing institutes for industrial research on university campuses had earlier caught the imagination of some topranking university officials, but this was quickly disposed of when a parliamentary sub-committee (the Cronyn committee) struck in April 1919 discovered that university faculty were adamantly opposed to "bargaining with manufacturers" (University of Toronto Professor Lash Miller, Cronyn Committee Proceedings, June 4, 1919: 99; cited in Lamontagne report, 1970: 31). At the time, Canadian universities modelled themselves after the humanistic traditions of Oxbridge. It was difficult enough for fundamental scientific research to gain a foothold in these institutions; to collaborate with industry was virtually unthinkable. In this era, teaching was the only legitimate activity.

NRC's views closely followed those of faculty on this matter, arguing that universities would subvert their role by conducting industrial research. Instead, government was persuaded by Dr. A.R. Macallum, the NRC's first chair, to construct a laboratory complex for the research council, in order to allow them to develop the new technologies Canada needed to keep pace with other nations, and to retain scientific talent in the country. The obligation to serve industry was literally engraved in stone above the doors of the laboratories on Sussex Drive in Ottawa. However, it was difficult for researchers trained in the principles of basic science to adapt to the needs of industrial research. In order to retain its researchers, NRC increasingly focused on fundamental inquiry.

Between 1916 and 1939 the NRC grew from one full-time employee and an annual budget of $\$ 91,600$ (US $\$ 90,000$ at then-current exchange rates) to 2,000 employees and a budget of close to $\$ 7$ million (US\$6.3 M) within months of the start of the Second World War (Lamontagne report, 1968-77, vol. 1: 61). During the war, Canadian scientists worked closely with British and American colleagues on the front lines of advances in microwave techniques, jet engines, digital computers and nuclear power. They were intent on continuing this momentum into the post-war era.

However, Canadian university administrators rarely encouraged "research" before the mid-1950s, being preoccupied with teaching returning war veterans and other undergraduates. For example, according to Phillipson (personal correspondence), C.D. Howe's R\&D Branch began an annual inventory of university research in 1946 but gave up the project in 1949, upon discovering that scientists were "faking the results, to conceal from university authorities how much they were diverting from teaching to spend on research." This resistance slowly began to change after Sputnik and the Canada Council's creation in 1957. While the "red scare" served to justify spending for scientific and technological research, the Canada Council, established as the main granting agency for research in the social sciences and humanities, extended funding to a broader base of academics. Federal expenditures devoted to R\&D grew from an estimated $\$ 5$ million (US $\$ 4.5 \mathrm{M}$ ) in 1939 to over $\$ 200$ million (US\$196 M) in 1959 (Lamontagne report, 1968-77, 
vol. 1: 64).

In 1944, then-NRC President C.J. Mackenzie proposed that state science defer leadership of the post-war knowledge economy to industrial demands and academic opportunities. The role of government science was simply to fill in the gaps, he said, by funding central laboratories for fragmented industries, or putting university scientists in contact with scarce facilities like nuclear reactors. But with few notable exceptions, in the post-war era industry and universities did not demonstrate this type of leadership in exploiting new knowledge.

Thus, unexpectedly, it was state science that moved ahead fastest, 1945-60, mainly because its top managers had the available funding (if not always the manpower) and [few] in industry or academe objected. By 1955-57 the whole of federal state science had been reconstituted and was humming along nicely. Expansion and reorganisation of NRC academic grants 1950-60 allowed top planners to suppose academic science was now in good shape. (Phillipson correspondence)

Much of this period coincides with the presidency of Dr. E.W.R. Steacie, who ran the NRC from 1952 until his death in 1962. Steacie focused on stabilising Canada's universities, believing this would best serve the needs of industry in the long term.

[T] he development of industrial research involves first the strengthening of university post-graduate schools, and secondly, ensuring that the best graduates remain in the universities to train further research students. It is possible to have first-rate university research with little or no industrial research, and in fact, this has been our history. It is absolutely impossible to have first-rate industrial research with- out first-rate university research. (Steacie, 1965: 159-160)

For Steacie, it was essential that Canada build a critical mass of scientists proportionately on par with Britain and the USA, not to be like those countries, but to transcend its colonial status and be independent of them (1965: 165-166). He thought this goal was prefaced on developing original high quality industrial research, which in turn required educating scientists and engineers in the fundamentals of their field, carefully nurturing the scientific imagination and avoiding contact with industry at an early stage.

There is no reason why an engineering student should ever have seen a plant or a mine before he graduates. 'Practical' knowledge can be acquired on the job and is certainly not a proper part of a university education. (Steacie, 1965: 48)

He believed universities were the major source of original ideas, a result of their comparatively low levels of co-ordination and planning.

[T] he university is... inefficient in the cost accountant's sense of the word. This is its greatest hope. There is nothing more antagonistic to original thought than business efficiency. In fact, as long as the universities can remain inefficient there is hope for the world. (Steacie, 1965: 38)

Consequently, under his presidency, he stated that the NRC strove "to be as similar to a university laboratory and as unlike a government department as it is possible for us to be and still carry out all our functions successfully" (Steacie, 1965: 142). Addressing faculty and students at a management conference held 
at Queen's University, he advised that

The important thing is that in any well run laboratory there must be a conscious and continuing effort to reduce organisation and planning to a minimum, to have as few committees as possible, to write reports as infrequently as possible, and to regard 'coordination' as a dirty word! (Steacie, 1965: 132)

An apparently unconventional candidate to lead a national policy instrument intended to coordinate science and develop industrial research, Steacie was convinced that the only way for the NRC to adequately support industry was to do so indirectly, by providing an infrastructure based on university research and the provision of university-trained professional scientists. However, this broad interpretation of its mandate to meet industry's needs failed to impress the Royal Commission on Government Organisation, (or the Glassco Commission), established in 1960 to assess the efficiency and economy of all government departments.

\section{The Glassco Commission}

Established under the Diefenbaker Conservatives, the Glassco Commission spanned a general election, reporting to Lester Pearson's Liberal administration in 1962. The commission examined the organisation, management and coordination of federally funded research activities in industry, universities and federal institutions. Finding that "the whole post-war expansion of government scientific activity has proceeded on a piecemeal basis without adequate co-ordination" (Glassco report, 1962: 218), the commission concluded that the system had failed to function as intended. Blame was placed on the armed services and, in particular, the NRC. A number of charges were levied at the latter. In the commission's view, the NRC had: focused undue attention and resources on the university grants program, in which its members had vested interests; neglected broad national policy goals; compromised its impartiality as a government advisor by operating its own laboratories; and most significantly, failed to promote industrial research:

One of the original purposes of government in devoting money to research was to encourage and stimulate Canadian industry. From being a primary goal this has, over the years, been relegated to being little more than a minor distraction.... At present there is a wide-spread feeling that fundamental research is the only activity adequately recognised within the National $\mathrm{Re}$ search Council. (Glassco report, 1962, vol. 4: 230, 271)

In short, Glassco famously concluded that NRC had "turned away" from industry. According to Phillipson, this conclusion was partly the result of an unhappy accident. The innovative NRC-IRAP program was not accounted for by Glassco because the report,

although published in 1962, was drafted in 1961 before IRAP was announced. The first draft was twice shortened and rewritten and extra paragraphs were added to cover IRAP, but the main text stood intact, with its charges that the Advisory Panel had never introduced any innovative policies and the NRC had 'turned away' from its duty of promoting industrial research (Phillipson, 1983: 16).

Glassco's damaging accusations of incompetence, indifference and partiality 
engendered vociferous protests from NRC's scientists and bureaucrats. Opinion from informed observers is divided on the justification for these protests. The OECD, for example, commenting on the reaction, noted that "many, no doubt, recognised that there were grounds for the criticism expressed by the Commission, but the majority protested against its recommendations" (OECD, 1969: 63). On the other hand, Phillipson argues that NRC was actively undertaking industrial research, as required, for companies who lacked in-house personnel or facilities. Sponsoring companies, however, which were expected to pay a portion of the costs, often insisted on confidentiality to protect their commercial interests. As a result, even among NRC scientists, little was known about this aspect of the Council's activities.

Faithful observation of these [confidentiality] provisions meant in practice that public scientists (NRC) did not know what their colleagues were doing in the way of commercial research, and top laboratory managers did not record corporate research activities in the ways that suited state-assigned applied science (e.g. on railways, wheat, etc.). This institutionalised an 'information gap' which became (in my opinion) positively vicious in the Glassco Report..., which relied for factual information on corridor gossip i.e. the researchers' social culture more than on documented records. (Phillipson correspondence)

The Glassco report recommended an institutional framework aimed at making government $R \& D$ activities more cohesive. Major structures in this framework included a permanent Science Secretariat to provide advice; a Science Council responsible for long range plan- ning; and the appointment of a minister responsible for science. The first two recommendations were put into effect: a Science Secretariat was established in 1964 and the Science Council of Canada began operations in 1966. The government hedged on the recommendation to appoint a minister for science. Instead, the minister who chaired the Privy Council Committee on Scientific and Industrial Research became the de facto science minister, albeit without designation (Dufour \& de la Mothe, 1993: 13).

However, the institutional framework envisioned by the Glassco Commission was substantially weakened in practice. Upon receiving the report, Prime Minister Pearson asked C.J. Mackenzie, former NRC president, for his opinion. Mackenzie advised against the substance of the Glassco findings in order to protect the "rights and privileges" of existing government institutions (Hayes, 1973: 47; Lamontagne report, 1970: 106). He proposed a compromise that effectively undermined the report's intent. The Glassco Commission's visions of a coherent and efficient central machinery for science policy disintegrated into a disorienting bureaucratic maze.

Nevertheless, the Glassco report established a policy environment more hospitable to promoting industrial research, the co-ordination of R\&D activities and research management. A number of government initiatives intended to bring academic research closer to the needs of industry were designed in the 1960s. Among these, the Industrial Research Institute Program, established by the Department of Industry in 1966, provided "seed funding" to universities to establish research institutes dedicated to working with industry. Legislative tools 
were also introduced; in 1967 government passed the Industrial Research and Development Incentives Act which was intended to foster academy-industry collaboration in research focused on solving industrial problems.

By the end of the decade, the Glassco Committee's criticisms were echoed in several other policy documents. In an extensive survey of Canada's science and technology infrastructure, OECD examiners agreed there was a lack of coordination, noting that "the observer of Canadian science policy often finds himself on shifting and unknown ground. New structures that are not always readily and precisely defined, appear side by side with other organisations left over from another period" (OECD, 1969: 63). The Science Council of Canada's 1968 report Towards a National Science Policy for Canada advocated greater collaboration between university, government and industry scientists and more use of multidisciplinary research teams. It also suggested that government laboratories work closely with industrial and university sectors, not as research performers but as research initiators and coordinators (Science Council of Canada, 1968: 26). The OECD and Science Council reports substantially contributed to the deliberations of the Lamontagne Committee.

\section{The Lamontagne Committee}

In November 1967, the Senate, Canada's Upper House, appointed a Special Committee on Science Policy chaired by economist Maurice Lamontagne. The Lamontagne Committee's mandate was to review the long-term financial and structural requirements for establishing a dynamic and efficient science policy for Canada. Mindful of the need for international comparisons, and of the nation's historical and geographic peculiarities, the Lamontagne Committee provided an exhaustive analysis of Canada's overall R\&D expenditures; federal funding of individuals, universities, industries and other groups; performance of R\&D in federal government laboratories; and the culture of science in Canada. The committee's findings were issued in three major volumes over the course of a decade (1968-1977).

The report was unique among Canadian policy documents in that it questioned the status of academic science as an intellectual endeavour that held itself apart from society and claimed special rights and privileges. The report demythologised the "Republic of Science" and positioned science as a social activity, like any other, with a mode of organisation and normative structure that were just as open to critical analysis. At the core of the report was an attack on the "personalist" mode of conducting science policy. The committee argued that scientific elitism had driven Canadian science policy from the time the NRC was established in 1916 (Lamontagne report, 1968-77, vol. 1: 268). They cited Steacie's proud comment that " $[\mathrm{w}] \mathrm{e}$ are, in fact, one of the few countries which has recognised the fundamental fact that the control of a scientific organisation must be in the hands of scientists" (Steacie, 1965: 119; cited in Lamontagne report, 1968-77, vol. 1: 269). Such freedom, the committee argued, "cannot be justified as a general principle for the organisation of scientific progress when the tremendous cost of research has to be met mainly by public funds and when 
the good and bad effects of science and technology on society are becoming so far-reaching" (Lamontagne report, 196877, vol. 1: 270-271).

The Lamontagne Committee proposed that "permanent steps should be taken to bridge the gap between the academic and industrial sectors" (1968-77, vol. 2: 521). Investment in scientific research needed to reflect national priorities and give special importance to industrial research. Funded research should be managed and evaluated in order to terminate less viable projects and shift investments to new priorities. Government research must be reoriented towards serving its original goal the needs of industry. Finally, the organisational structure for the R\&D system should be based on economic forecasting and planning for future industrial needs, giving industry priority while taking into account the needs of science and Canadian society.

Lamontagne was enthusiastic about the whole business of planification-economic forecasting and planning - and its potential for fostering "innovation". The latter word entered the Canadian policy discourse about halfway through the "Lamontagne decade". Seduced by the idea of innovation, the committee also embraced "the new quasi-economic discipline of science policy" that went with it (Phillipson correspondence). Committee members and staff were thus "naively enthusiastic about both (a) the notional completability of the Science Policy model (Leontieff matrix) and (b) its political appeal to actual politicians" (Phillipson correspondence).

The Lamontagne Committee failed to understand "the garbage can model of rationality" (Cohen et al., 1972) that po- litical decision-making is not fact-based. Therefore, the provision of ever-increasing amounts of data to "actual politicians" tends to be a waste of time and effort. Consequently, despite the years that went into producing the report, "it fell dead from the press", winning neither the attention nor support of then Prime Minister Pierre Trudeau nor that of his cabinet (Dufour \& de la Mothe, 1993, 21, fn. 13). The exercise is a classic example of how not to change policy. Given the power of entrenched elites, whether political or scientific, to resist change, it is wise to identify "advocacy coalitions" or "policy networks" in advance, and work through them to find policy brokers who can influence the political agenda and who are willing to champion the changes (Sabatier, 1988; Smith, 1998).

One recommendation that was implemented was the creation of a Ministry of Science. In 1971, the Ministry of State for Science and Technology (MOSST) replaced the Science Secretariat. Its mandate was initially modest - providing advice on science and technology policy, as well as creating and coordinating science policy. But gradually its responsibilities were extended to the priorities and planning of Canada's overall science and technology effort. Eventually its authority subsumed part of NRC's mandate. There was a political will at work in the expansion of MOSST. As a Crown corporation, NRC was beyond direct interference by politicians and the central agencies of state. The only way to control it was to systematically strip away its budgets and responsibilities, and transfer them to another, more subordinate agency. A similar fate awaited the Science Council (disbanded in 1992) and 
other autonomous bodies as policy became increasingly politicised.

In 1977, the NRC and the two other granting councils (the Medical Research Council and the Canada Council) were restructured. The NRC was required to devolve its responsibility for supporting faculty and graduate student research to a new agency, the Natural Sciences and Engineering Research Council of Canada (NSERC) which then fell under the administrative authority of MOSST. In 1978, MOSST assumed authority over the Social Sciences and Humanities Research Council of Canada (SSHRC) after the Canada Council was reorganised. This restructuring gradually eroded the autonomy of all granting councils.

The election of a Progressive Conservative government in 1984 signalled a shift to the right on the political spectrum. The development of a national science policy that would steer academic science toward meeting the needs of Canada's international competitiveness was high on the agenda of the new government. In 1986, the government introduced a matching funds policy requiring the granting councils to work in partnership with the private sector in efforts to increase the level of university-industry collaborations. These goals were part of the ideologically driven reform of public sector institutions, known as 'new public management', occurring in OECD countries generally at this time. In December 1986, following an intense period of federal/provincial meetings of science and technology ministers, both levels of government reached an agreement on the broad components for Canada's first national science and technology policy. The agreement was formally signed by federal, provincial and territorial S\&T ministers in March 1987. In the following month, InnovAction: The Canadian Strategy for Science and Technology, was announced with $\$ 1.5$ billion (US\$1.08 B) in funding. By merging MOSST with the Department of Regional Industrial Expansion (DRIE), InnovAction established a new "superministry" - Industry, Science, and Technology Canada (ISTC).

At the same time, the government unveiled its new flagship strategy - the establishment of prestigious Networks of Centres of Excellence (NCE) of academy/industry partnerships. Under the same legislation, however, additional funding was also allocated to the existing flagship partnering strategy - NRC's Industrial Research Assistance Program (IRAP). While NRC itself was in the political "out" box, NRC-IRAP was extremely popular, and its networks reached across the country. The IRAP and NCE programs have remained the two key instruments in successive policy frameworks committed to serving the research needs of industry, and furthering Canadian competitiveness in a global economy.

\section{Policy Instruments}

In this section we describe the IRAP and NCE programs and contrast the different approaches they adopt towards their mandates to serve industry. Both are publicly funded of course, and both hover on the boundary between academic and industrial science, public and private knowledge. But IRAP is anchored on the industry side of the public-private divide, while NCEs are anchored on the university side. Also, each is pursuing a somewhat different end. Broadly speaking, IRAP is about enhancing the capaci- 
ties of existing industries while the NCE program's focus is on creating new receptor capacity. We argue, however, that IRAP provided government with an important model on which to base the NCE program.

\section{Industrial Research Assistance Program (IRAP)}

As stated earlier, under Steacie NRC focused on getting the supporting grants system for university research in order. Only then did it turn its attention to industrial science and try to create incentives to encourage industry to develop its own resources. Industry resisted these efforts. In the economic and intellectual climate of the post-war period, there was an abundance of available technology for a rapidly growing consumer market, and manufacturers and producers felt little incentive to innovate (Phillipson correspondence). The great precedent in encouraging them to do so was the Industrial Research Assistance Program (IRAP), established in 1962, after the death of Steacie.

IRAP dates from when the NRC still ran along personalist ("old boys' network") lines. Its prehistory was as the Technical Information Service (TIS) founded by Mackenzie in C.D. Howe's Department of Reconstruction and Supply in 1945. It was reenergized in 1962 by a retired air marshal named Ralph McBurney. TIS gave "knowledge subsidies" to industry in the form of technical advice. The 1962 innovation proposed to add cash subsidies as well. IRAP wanted to give grant funding to industry for private research, in the same way that universities received grants for public research. According to Phillipson, the idea of giving public money to private industry "was such an extraordinary precedent that it took a year's preparation by the Advisory Panel on Scientific Policy and required Treasury Board and Cabinet approval" (Phillipson correspondence; see also Phillipson, 1983).

In the aftermath of the Lamontagne report the NRC reorganised several times, trying out different corporate structures. In one of these, then-President Schneider merged IRAP and TIS under the name of the former and recruited Keith Glegg, of Marconi, in 1977, to run it as Vice-President of Industry and Technology Transfer. In some ways Glegg's appointment reflects the continuity of the personalist system - the connection between Schneider and Glegg was made through John Steacie, son of the former president (NRC source). Yet Glegg's direction of IRAP proved masterful. He was an aeronautical engineer with a gift for charismatic leadership and an eye for talent. As an industry scientist, he could mediate between the worlds of public science and industry needs. It was he who recruited the field army referred to earlier. He sent them out, basically with a blank cheque and his blessing, to help industries across the country meet their research needs (NRC-IRAP interviews, $23 / 01 / 01)$. $^{5}$

Glegg recruited from outside the federal government, not only to get the numbers and regional coverage, but also to get the intellectual diversity. He looked for people who were comfortable in both academic and industry cultures, but he did not want laboratory researchers. He needed people with between ten and twenty years' experience in industrial science. He borrowed them from provincial PROs, university-industry li- 
aison offices, associations of consulting engineers, community colleges and technical institutes, federal agencies, engineering faculties and from the NRC itself (NRC-IRAP interviews, 23/01/01; Doutriaux \& Barker, 1995.) NRC provided about one-third of the Industrial Technology Advisors (ITAs), as the field staff were called. They constituted the organisational core around which the non-NRC ITAs clustered. Non-NRC staff were paid by their own institutions which received salary support from IRAP to release them. Glegg felt that the organisational complexity involved in importing "outsiders" into a government agency, was more than offset by the intellectual capital they brought. The diversity of backgrounds also contributed to IRAP's strong, distinctive client-based culture, which has been key to maintaining loyalty within such a distributed and diverse network of employees. IRAP maintained offices in every province, so ITAs were "the human face of innovation" (IRAP web site) for small and midsized enterprises (SMEs) across the country. They took with them into the field Glegg's definition of industry research: anything a firm has to do to frame the question that technology has to answer (NRC-IRAP interviews, 22/01/01).

Helping firms frame researchable questions and answer them was the mandate of the ITAs. These 260 agents were gateways in extended actor-networks of resources and facilities. Through them, SMEs had access to some 130 public and private research- and technology-based organisations that were partners in the field network. In the manner that John Law (1992) calls "heterogeneous engineering", clients, their technical problems, ITAs, provincial labs, federal labs, industry labs, engineering prototypes and federal money were all linked together in long chains dedicated to helping Canadian SMEs innovate. Lubricating the chain was the funding autonomy of ITAs. They possessed delegated authority of up to $\$ 100,000$ (US\$84,000) meaning that they did not need permission to take action on behalf of a client. Their decisions were reviewed after the fact by local committees. As IRAP's "mini-history" states,

The confidence to delegate downwards in IRAP, at a time when government in general moved decisions upwards, was based on IRAP's confidence in the quality and professionalism of the Network staff and the establishment of local review and decision committees (IRAP web site: 2).

Everything was focused on the firm, the context of application. This represented not only a radical departure from NRC's past emphasis on the context of discovery, but also a strategic reinterpretation of NRC's mandate for industrial relevance. In terms of the latter, IRAP contrasted itself favourably with the departments responsible for industry (then MOSST and DRIE). Compared to NRC's nation-wide field coverage, these departments were said to be "trying to connect with industry by dropping leaflets from the $20^{\text {th }}$ floor of an Ottawa skyscraper" (NRC-IRAP interviews, 22/01/ 01). While MOSST and DRIE were listed in the telephone directory's "blue pages" under "government", IRAP was listed in the yellow pages under "businesses". Government, in general, was far removed from the world of industry. But IRAP knew first-hand "the emotional turmoil of entrepreneurs, who risked failure every time they made a decision". 
IRAP's ITAs were right there on the factory floor. They knew how entrepreneurs felt, and were able to respond in person (NRC-IRAP interviews, 24/01/01).

Over the years, IRAP earned the approval of scientists, industrialists, politicians and bureaucrats alike; it was considered a model of how to deliver effective innovation support. It received numerous positive appraisals from various reviews, and was one of the few programs to consistently earn budget increases in the face of continuing federal budgetary cuts (McFetridge, 1995). In assessing services and subsidies to industry, the government's 1985 Task Force on Program Review concluded that "IRAP works" and suggested that the government consolidate its technology transfer efforts within it (Minister of Supply and Services, 1985: 429; cited in McFetridge, 1995: fn 63).

That would have been a sensible option but NRC was a Crown corporation and difficult to control politically. Consequently, MOSST decided to reinvent the wheel. It took the concepts of distributed networking and technology transfer pioneered in NRC-IRAP and formulated a new program called "Networks of Centres of Excellence".

\section{Networks of Centres of Excellence (NCEs)}

On 13 January 1988, Prime Minister Brian Mulroney announced his intention "to establish networks of researchers and scientists across the country to conduct world-class research in areas crucial to Canada's long-term competitiveness" (Mulroney, cited in ARA Consulting Group Inc., 1997). ${ }^{6}$ Funding of $\$ 60$ million (US\$50 M) per year, for four years was committed. Turning NRC-
IRAP on its head, these networks would be based in universities and would reach out to industry for assistance. But the idea was the same as IRAP's: investing in people (researchers), rather than bricks and mortar (universities and hospitals), and partnering with existing technical resources across the country, whether in industry, academia or government. Like IRAP's ITAs, network researchers would be paid by their own institutions but build a strong sense of belonging to a larger national entity-the network.

Yet in contrast to the IRAP network, NCEs would be parasitic on their member institutions. The universities and hospitals would still pay the researchers, provide space and equipment, and pay the overhead on their labs. But there would be no compensation for doing so. NCE funds flowed to the researchers through separate "network offices". While they used university financial systems, network offices had no duty of accountability to the university. Their reporting allegiance was to the NCE directorate in Ottawa. So these new networks "floated on top" of existing structures, enabling the federal government to circumvent university power and autonomy, and provincial jurisdiction, by creating a national research capacity directly responsive to the needs of industry and the economy.

This was a system of national research networks “without walls". Like IRAP's distributed network, the ephemeral and virtual nature was important. While "centres of excellence" had become a feature of science policies world-wide, the networking of such centres was a unique response to Canadian geography, provincial diversity and limited scientific resources. Building separate 
"bricks and mortar" centres would have been prohibitively expensive and would have drained talent from existing institutions. Instead, they linked together the best of the best, left them in place, and invested in research.

NRC was not formally involved in this initiative (although ITAs were initially called on for advice on industry partnerships.) NCE had been championed by ISTC, and later partially captured by the research councils. As a result, few within the councils or ISTC knew how to go about achieving the networking and technology transfer that IRAP did so well, or even how to administer such an initiative. (But note that NSERC had successfully implemented a large scale network called Lithoprobe in the early 1980s.) Broadly speaking, the NCE program was invented on the fly, and rules and expectations were modified as the program and the networks co-evolved. The lack of structure is apparent in the delays that occurred at the "front end". From the January 1988 announcement it took two and a half years before the first tranche of funding was released to the 15 successful networks in the late summer of 1990. The learning curve was especially steep in the first phase, 199094, as faculty members developed new skills in networking with government and industry sectors and began for perhaps the first time to understand the nature of Canada's industrial cultures (Policy interviews, 10/5/99, 1:10). Thereafter, it stabilised somewhat. After a comprehensive evaluation in 1996 (ARA Consulting Group Inc., 1997), the NCE program was made permanent in 1997, with an annual allocation of $\$ 47.4$ million (US $\$ 31 \mathrm{M}$ ), subsequently increased to $\$ 78$ million (US\$50 M) in the 1999 bud- get. At the same time, a controversial 14 year sunset clause was announced, meaning the most successful of the surviving original networks would exit the program in 2005.

Like IRAP, one of the NCE program's goals was to break down barriers between public and private science, so that results and resources could be shared and transformed into commercial opportunities. Throughout the three phases of the program, more and more emphasis has been placed on the networking and technology transfer criteria. While it is questionable whether federal ambitions have been achieved in this regard, the reported linkages are impressive. By 1999-2000, NCE actor-networks enrolled some 1100 researchers, 61 Canadian universities, 39 hospitals, 130 federal and provincial agencies, 200 other organisations and about 475 companies (of which some $10 \%$ were network "spin-offs"). Clearly, like IRAP, NCEs are helping to develop regional systems of innovation by distributing research capacity and start-up activities across the country. Recently, the NCE directorate has also been encouraging international linkages.

Public investment in the program is high. Table 1 shows $\$ 630$ million (US\$ $403 \mathrm{M}$ ) in cash transfers from fiscal 1990 to fiscal 2000, not including university infrastructure, prior funding of fundamental research now moving towards the market, or the salaries and benefits of university researchers. The latter were conservatively estimated by the program to be approximately $\$ 100$ million (US $\$ 64$ M) a year in 1996 (NCE Annual Report, 1996-97). With the growth of the program, that figure will have doubled. Indeed, according to one federal informant, universities have contributed at 
least as much as the program itself over the years, by absorbing the salaries, benefits and overhead of researchers. In contrast, the private-sector is credited with $\$ 75$ million (US\$48 M), or approximately $10 \%$ of the program's $\$ 730$ million (US $\$ 467 \mathrm{M}$ ) cash budget. Various reporting anomalies suggest this private-sector figure may be overstated. The same anomalies prevent any reliable estimate of "in-kind" contributions from industry partners. Since September 2000 , however, networks have been required to submit audited annual reports, so these problems should eventually resolve.

A narrow economic argument might suggest that industry's lacklustre "buyin" indicates the NCE program has not provided an adequate return on public investment. But using a broader argu- ment, in terms of the generation of new knowledge and its effects on society, many would argue that the NCE program has more than repaid its costs. The program claims to do several things. One, it professes to keep talent in the country by providing a large enough research structure. Two, it spins-out talent into small industries that would not have started without network incubation. These companies help to keep people in the country and they generate cash flows and income for the system. Three, the program asserts that it has helped shift the research orientation of the "Republic of Science" toward the interests of industrial research, which indeed was its main objective from the start (Fisher $e t$ al., 2001). The extent to which the NCE program has actually succeeded in achieving these feats is an open question

Table 1. Total cash contributions to NCEs, 1990-2000 (excludes in-kind gifts and overhead support)

\begin{tabular}{|lrr|}
\hline Agency & $\mathbf{C \$ M}^{\mathbf{1}}$ & \% \\
NCE Grants & & \\
Federal Agencies & 509.5 & 69.9 \\
Administration/sundry & 27.3 & 3.7 \\
Sub-total - Federal & 14.2 & 1.9 \\
Provincial Agencies & $\mathbf{5 5 1 . 0}$ & $\mathbf{7 5 . 6}$ \\
Sub-total - Government & 45.8 & 6.3 \\
Universities (direct only) & $\mathbf{5 9 6 . 8}$ & $\mathbf{8 1 . 9}$ \\
Other - hospitals and tax-exempt foundations & 8.5 & 1.2 \\
Sub-total - public supported institutes & 48.4 & 6.6 \\
Industry contributions & $\mathbf{6 5 3 . 7}$ & $\mathbf{8 9 . 7}$ \\
Total Cash & 75.0 & 10.3 \\
& 728.7 & $\mathbf{1 0 0 . 0}$ \\
\hline
\end{tabular}

1) Canadian dollar worth an average of 64 cents US in this period

Source: compiled from NCE annual reports. 
that will be addressed in our ongoing studies.

Originally, the program's architects anticipated major partnerships with large multinationals, but it soon became clear that these would be the exception rather than the rule. So the goal became to create industrial and investment capacity that did not yet exist: new companies and new sources of venture capital. That being the case, it is hardly surprising the overall private investment in NCEs is low. Rather, we must look at the trend as networks mature, and the trend line is rising. The main source of growth is from equity in these network spin-offs. As these companies raise capital and mature, more returns will flow back to the networks.

Nurturing SMEs is a laudable goal, as NRC-IRAP showed. However, there is an important difference between the two programs that gets lost when NCEs move the academic research culture closer to application. Unlike IRAP, NCEs are built on the fundamental research of scientists in public universities. In this, they are more akin to the Canadian Institute of Advanced Research (CIAR) and NRC's public laboratory networks than IRAP. In terms of models for the NCE program, if NRC-IRAP showed how to manage the "application" end of the research spectrum and relations with industry, then CIAR, founded in 1982, provided a model for the interdisciplinary linking of researchers engaged in fundamental enquiry. Arguably, the increasing focus on commercial goals distorts the accumulation of the underlying knowledge on which the whole edifice rests. As the chair of one of the networks stated during an interview,
Eventually the program became so focused on private sector involvement that, in a way, you were simply doing applied and strategic research with and for companies. And you were basically undermining your fundamental research base.(JAG Source-8)

The networks that will see the sunset of federal funding in 2005 are scrambling now to replace it, with increasingly speculative venture capital arrangements and intellectual property deals. It seems that more effort is flowing into finance than research at this stage, yet it is doubtful whether the effort is worthwhile. The new companies are too small to support the underlying research required to generate applications and, without that, the networks will have difficulty retaining their integrity.

Basically, we did an analysis of the pri-
vate-sector income we could expect to
generate from the companies we could
spin out...based on our past experi-
ence. And of course it's not sustainable.
You can't finance the fundamental re-
search and there's just no way these
companies have the financial capacity
to fund the fundamental research, be-
cause they are not big enough. It's as
straightforward as that. (JAG Source-9)

Because Industry Canada (previously ISTC) did not understand the way science works, the underlying premise of the NCE program was flawed. The policy envisioned ideas moving through the network from discovery to application the linear, pipeline model. Logically, then, when all the ideas had been moved through, the network would be "finished" because they would have put all their ideas into applied research. At this point, the funding tap could be turned off. This model ignores the complex interactions that take place as discovery 
and development feed into each other. Important fields are in constant motion; "you've got to stay with them if you're going to stay hot. The people doing policy don't have any experience of that" says the source quoted above.

However, despite mistakes at the start and the sunset controversy, a lot of policy learning has taken place as the program has grown and matured. The model pioneered by IRAP and extended by the NCEs is becoming the preferred way to practice science, whether the locus of that science is public or private.

Number one, if you are a thinly spreadout country, and want to be part of new knowledge development and its application, then you damn well have to create some kind of national network structure or else you are dead in the water. You become totally derivative. So in that sense, they have proven that they can do that. That they can operate these things. (JAG Source-15)

\section{Concluding Remarks}

Networks of expertise are deeply embedded in Canada's geography and history. If we had looked further back for precursors for current alliances, we could have pointed to the fur trading networks of the Hudson's Bay Company, which were built on the trading networks of Canada's First Nations (Innis, 1930; Ray, 1978). From the time of Confederation, Canada's spatial problems, small population, and underdeveloped resources encouraged a strong federal presence in scientific development. The National Research Council represents the first federal attempt to design a general science policy. However, the objectives established for it failed to consider the state of industrial
$R \& D$ and required federal incursions into provincial jurisdiction to build a critical mass of scientists. Federal responsibility for economic development gave government a legitimate means to support the research and training of university scientists and engineers.

Beginning in the 1960s, policy documents focused on ways to improve the coordination of federally funded research. Suggestions made by the Glassco and Lamontagne reports were largely ignored in their time, but focused the political will on altering scientific cultures as a means to fulfil the promise that PROs held for economic development. By the 1980s, Canada's political culture was more fiscally conservative yet more prone to act on policies that viewed science and technology as forces to advance Canada's international competitiveness. The period brought greater federal/provincial collaboration, resulting in Canada's first national science policy, which strengthened the Industrial Research Assistance Program and established the Networks of Centre of Excellence program.

In the process, the old dichotomies have been steadily eroding. Instead of the closing that takes place when boundaries between public and private and research/ development are fixed, we are increasingly seeing the opening of a "third space", between the polarities, where PROs and industry meet. Research in this space, that Stokes (1997) calls "Pasteur's Quadrant", is dedicated to both use-based understanding and understanding-based use. In many senses it is an artificial space, an artifact of policy and funding. But in another sense it is also a return to an older tradition where knowing how and knowing that - artisanal knowledge 
and scientific knowledge - are indissolubly bound together in fruitful union (Jackson, 2000).

\section{Acknowledgements}

The authors wish to acknowledge the support of the Social Sciences and Humanities Research Council of Canada: Strategic Grant \# 410-98-1577, Donald Fisher, Principal Investigator.

\section{Notes}

1 In this article, we define public research organisations (PROs) as universities, hospitals, government laboratories and other state agencies that conduct scientific research and are funded primarily by the public purse.

2 See Phillipson $(1983,1991,2000)$ and Atkinson-Grosjean/Phillipson personal correspondence. By virtue of his oral history projects in the 1970s and 1980s, Phillipson is an authority on the National Research Council and the evolution of Canadian science policy. He has communicated an enormous amount of background material to Atkinson-Grosjean in a series of letters over the period 19982001. His collegial willingness to share his scholarship has enriched our understanding and we acknowledge his contribution to this policy history, which draws directly on the correspondence.

3 J.W. Dawson, professor of geology and paleontology at McGill University, became the university's principal in 1854, and later, first president of the Royal Society of Canada, the country's first general organisation for science (Doern, 1972: 134). During the 1920s, J.H. Grisdale as Deputy Minister of the Department of Agriculture, and Charles Camsell as Deputy Minister of the Department of Mines, successfully blocked the NRC from fulfilling its mandate to coordinate activities of federal departments engaged in sci- entific research (Thistle, 1966: 261). Dr. Chalmers J. Mackenzie headed the NRC during the SecondWorldWar, then led the Atomic Energy Control Board and Atomic Energy of Canada Ltd. (Porter, 1965: 432). Dr. E.W.R. Steacie left McGill University to become head of NRC's chemistry division in 1939. He was appointed NRC's vicepresident in 1950 and its president in 1952, holding the latter post until his death in 1962, at which time he was widely acknowledged the 'leader of Canadian science' (Babbit, 1965: 3).

4 For a comparative analysis of Canadian and USA science policies, see AtkinsonGrosjean (2001).

5 We wish to acknowledge the generosity of Dr Morley Lipsett, of the Centre for Policy Research on Science and Technology (CPROST) at Simon Fraser University in Vancouver, in allowing us to draw on interview materials collected by AtkinsonGrosjean during a CPROST project on the history of IRAP.

6 See Fisher, Atkinson-Grosjean and House (2001) for an empirical study of the NCE program's formation.

\section{References}

ARA Consulting Group Inc.

1997 Evaluation of the Networks of Centres of Excellence Program. Prepared for the NCE Program Evaluation Committee.

Atkinson-Grosjean, J.

2001 "Science \& Technology Policy and University Research: Comparing Canada and the United States, 1979 to 1999." International Journal of Technology Policy and Management 1, 2 (Spring).

Babbitt, J.D.

1965 “Introduction.” In Steacie, E.W.R., Science in Canada. Selections from the Speeches of E.W.R. Steacie. J.D. Babbitt (ed.). Toronto: University of Toronto Press. 
Banting, K., Hoberg, G. and Simeon, R. (eds.) 1997 Degrees of Freedom: Canada and the United States in a Changing World. Kingston: McGill-Queen's University Press.

Bobbio, $\mathrm{N}$.

1989 "The Great Dichotomy: Public/Private." In Democracy and Dictatorship. Cambridge: MIT Press.

Bourdieu, P.

1969 "Intellectual Field and the Creative Project." Social Science Information 8, 2: 89-119.

1988 Homo Academicus. Stanford: Stanford University Press.

Burchell, G.

1996 "Liberal Government and Techniques of the Self." In A. Barry, T. Osborne and N. Rose (eds.), Foucault and Political Reason: Liberalism, Neoliberalism, and the Rationalities of Government. Chicago: University of Chicago Press.

Callon, M.

1994 "Is Science a Public Good?" Science, Technology, and Human Values 19, 4 (Autumn): 395-424.

Cohen, M., March, J. G. and Olsen, J.

1972 "A Garbage Can Model of Organizational Choice.” Administrative Science Quarterly 17: 1-25.

Doern, G.B.

1972 Science and Politics in Canada. Montreal: McGill-Queen's University Press.

Dufour, P. and de la Mothe, J.

1993 "The Historical Conditioning of S\&T." In P. Dufour, and J. de la Mothe (eds.), Science and Technology in Canada. London: Longman.

Finnemore, M

1993 "International Organizations as Teachers of Norms: The United Nations Educational, Scientific, and Cultural Organization and Science Policy." International Organization 47, 4 (Autumn): 565-97.

Fisher, D., Atkinson-Grosjean, J. and House, D. 2001 Changes in Academy/Industry/State Relations in Canada: The Creation and Development of the Networks of Centres of Excellence. Minerva: A Review of Science and Policy (forthcoming).
Garrett, G. and Lange, P.

1996 "Internationalization, Institutions, and Political Change." In H. Milner and R. Keohane (eds.), Internationalization and Domestic Politics. Cambridge: Cambridge University Press.

Glassco Report

1962 Royal Commission on Government Organization. 5 vols. Ottawa: Queen's Printer.

Hayes, R.

1973 The Chaining of Prometheus: Evolution of a Power Structure for Canadian Science. Toronto: University of Toronto Press.

Innis, H.A.

1930 The Fur Trade in Canada: An Introduction to Canadian Economic History. New Haven: Yale University Press.

Jackson, M.W.

2000 Spectrum of Belief: Joseph von Fraunhofer and the Craft of Precision Optics. Cambridge, Mass: The MIT Press.

Lamontagne Report

1968-77 A Science Policy for Canada. Report of the Senate Special Committee on Science Policy. 3 vols. Ottawa: Queen's Printer for Canada.

Law, J.

1992 "Notes on the Theory of the Actor-Network: Ordering, Strategy, and Heterogeneity." Systems Practice 5, 4: 379-93.

McFetridge, D. G.

1995 Science and Technology: Perspectives for Public Policy. Industry Canada Occasional Paper Number 9 (July). Science and Technology Review. Ottawa: Industry Canada.

Mills, C. W.

1956 The Power Elite. New York: Oxford University Press.

Minister of Supply and Services

1985 Services and Subsidies to Business. Task Force on Program Review. Ottawa.

NCE Program

1996-97 Annual Report. (http://www.nce. gc.ca/books/ar/html/5.htm).

OECD.

1969 Reviews of National Science Policy: Canada. Paris: OECD. 
Offe, C.

1984 Contradictions of the Welfare State. Cambridge, Mass.: The MIT Press.

1996 Modernity and the State: East, West. Cambridge, Mass.: The MIT Press.

Phillipson, D.

1983 "Steacie Myth and the Institutions of Industrial Research." Scientia Canadensis 7, 25.

2000 "In response to a question from India about models of A/I collaborations." Dphillipson@trytel.com. In H-SCIMED-TECH@H-NET.MSU.EDU, Saturday 16 September, 09:17.

Porter, J.

1965 The Vertical Mosaic: An Analysis of Social Class and Power in Canada. Toronto: University of Toronto Press.

Powell, W. W. and DiMaggio, P.

1983 "The Iron Cage Revisited: Institutional Isomorphism and Collective Rationality in Organisational Fields." In W.W. Powell and P. DiMaggio (eds.), The New Institutionalism in Organisational Analysis, 1991 edn. Chicago: University

Ray, A. of Chicago Press.

1978 Give Us Good Measure: An Economic Analysis of Relations Between the Indians and the Hudson's Bay Company Before 1763. Toronto: University of Toronto Press.

Ringer, F.

1992 Fields of Knowledge: French Academic Culture in Comparative Perspective, 1890-1920. Cambridge: Cambridge University Press.

Sabatier, P.A.

1988 "An Advocacy Coalition Framework of Policy Change and the Role of PolicyOriented Learning Therein." Policy Sciences 29: 129-68.

Science Council of Canada

1968 Towards a National Science Policy for Canada. Ottawa: Queen's Printer and Smith, A. Controller of Stationery.

1998 "Policy Networks and Advocacy Coalitions: Explaining Policy Change and Continuity in UK Industrial Pollution Policy?" SPRU Electronic Working Papers Series, No. 29. University of Sussex: Science Policy Research Unit.
Steacie, E.W.R.

1965 Science in Canada. Selections from the Speeches of E.W.R. Steacie, J.D. Babbitt (ed.). Toronto: University of Toronto Press.

Stokes, D.E.

1997 Pasteur's Quadrant: Basic Science and Technological Innovation. Washington, DC: Brookings Institution Press.

Thistle, $\mathrm{M}$.

1966 The Inner Ring: The Early History of the National Research Council of Canada. Toronto: University of Toronto Press.

Unger, B. and van Waarden, F.

1995 "Introduction: An Interdisciplinary Approach to Convergence." In B. Unger and F. van Waarden (eds.), Convergence or Diversity? Internationalization and Economic Policy Response. Aldershot: Avebury.

Weintraub, J.

1997 "The Theory and Politics of the Public/ Private Distinction.” In J. Weintraub and K. Kumar (eds.), Public and Private in Thought and Practice: Perspectives on a Grand Dichotomy. Chicago: University of Chicago Press.

Janet Atkinson-Grosjean,

Dawn House and

Donald Fisher

Centre for Policy Studies on Higher

Education and Training,

University of British Columbia,

Vancouver, Canada

janetat@interchange.ubc.ca 